\title{
Responsabilidad pública en materia de violencia de género (Especial referencia a las hijas e hijos de madres maltratadas)
}

\author{
Public responsibility in the matter of gender violence \\ (Special reference to the daughters and sons of battered \\ mothers)
}

\author{
María del Carmen Peral López * \\ Abogada. Profesora de Derecho del Trabajo y Seguridad \\ Social. Departamento de Derecho Público y Privado \\ Especial. Universidad de Jaén
}

Recibido: 05/07/2019

Aceptado: 24/10/2019

doi: https://doi.org/10.20318/femeris.2020.5389

\begin{abstract}
Resumen. Las mujeres víctimas de violencia de género y sus hijas e hijos sufren una doble victimización, al haber vivido en un ambiente de violencia permanente dirigida en principio hacia sus madres, pudiendo llegar a ser triple cuando son testigos de este tipo de agresividad, que llega incluso a causarles la muerte. Tras el cese de la convivencia de la pareja no dejan de sufrir, en muchos casos, empiezan un régimen de visitas con el padre biológico, situación que los expone a un nuevo tipo de riesgo hacia ellos o a la madre a través de ellas y ellos. Este tipo de violencia es la llamada violencia vicaria. Tras las reformas normativas de 2015 , se siguen otorgando regímenes de visitas, estancias y comunicaciones a progenitores que infringen malos tratos a la madre y no han aumentado prácticamente las medidas de protección a los menores en estos supuestos tras casi cuatro años trascurridos desde la entrada en vigor de dichas reformas. Es cierto que la solución está en la preparación especializada, pero, mientras la deseada formación de los operadores jurídicos deja huella, hay que aplicar medidas de protección a los menores y dar un paso más tomando conciencia del daño que se está cometiendo, asumir la responsabilidad que le corresponde al Estado y articular medidas indemnizatorias al igual que en su día se hizo con las víctimas del terrorismo. Sorprendentemente, ni Ley Orgánica 1/2004, ni las legislaciones autonómicas han incluido definiciones de la violencia institucional, que conlleva la obligación de reparación del daño por parte del Estado y su traducción en indemnizaciones para las víctimas.
\end{abstract}

Palabras clave: violencia, género, institucional, responsabilidad, menores.

Abstract. The daughters and children of women victims of gender violence suffer a double victimization, having lived in an environment of permanent violence directed in principle towards their mothers, and can be triple when they witness this type of violence, which even

"mcarmen.peral8@gmail.com 
reaches cause them death. After the cessation of the cohabitation of the couple they do not stop suffering, in many cases, they begin a regime of visits with the father, situation that exposes them to a new type of violence towards them or to the mother through them and they, the called vicarious violence. In spite of the reforms of 2015, the visitation, stay and communication to parents that violate mistreatment of the mother continue to be granted, and practically no measures have been taken to protect minors in these cases in the three years since entry. in force of said reforms. While the desired training of legal operators leaves its mark, it is necessary to apply measures to protect minors and go a step further by becoming aware of the damage that is being committed, assuming the responsibility that corresponds to the State and articulating compensation measures as in his day was with the victims of terrorism. Surprisingly, neither Organic Law 1/2004, nor the regional legislations have included definitions of institutional violence, violence that entails the obligation to repair the damage by the State and its translation in compensation for the victims

Keywords: violence, gender, institutional, responsibility, Administration, minors.

\section{Introducción}

Desde el punto de vista político, las Conferencias mundiales sobre las mujeres han propuesto medidas concretas en materia de violencia de género y lo mismo podría decirse de las resoluciones aprobadas casi todas en el seno de la III Comisión de la Asamblea General Naciones Unidas, Organización Internacional pionera en abordar el problema de la violencia contra las mujeres. Tanto desde la visión política, como desde el análisis jurídico, la Organización ha aprobado medidas para combatir esta forma de violencia.

Desde el punto de vista jurídico, especialmente a partir de la aprobación en 1979 de la Convención sobre eliminación de todas las formas de discriminación contra las mujeres (CEDAW) ${ }^{1}$, y de la aprobación en 1993 de la Declaración de Naciones Unidas sobre la violencia contra las mujeres ${ }^{2}$, también ha habido un despliegue de actividades.

Es significativa la calificación de la violencia a la que se refiere el $n . \stackrel{0}{1}$ de la recomendación n. ${ }^{-19}$, confirmando que la violencia contra las mujeres es una forma de discriminación que le impide el ejercicio de los derechos y libertades fundamentales. De este modo, la recomendación confirma el encuadre de la violencia contra la mujer en la protección de los derechos humanos y las libertades fundamentales, lo que desmarca la cuestión del mero ámbito de la vida privada e incluso de las políticas sociales.

La DEDAW (The Declaration on the Elimination of Discrimination against Women), la CEDAW (The Convention on the Elimination of All Forms of Discrimination againts Women $)^{4}$, y el Convenio de Estambul ${ }^{5}$ establecen un catálogo de obligaciones que van des-

\footnotetext{
${ }^{1}$ http://www.inmujer.gob.es/elInstituto/normativa/normativa/docs/convencion.pdf.

${ }^{2}$ Aprobada por la Asamblea General de las Naciones Unidas en su resolución 48/104 del 20 de diciembre de 1993. "RESOLUTIONS: General Assembly, 48th session". un.org.

${ }^{3}$ El n.o 1 de la recomendación general n.o 19 afirma: La violencia contra las mujeres es una forma de discriminación que inhibe gravemente la capacidad de la mujer de gozar de derechos y libertades en pie de igualdad con el hombre.

${ }^{4}$ La Convención sobre la eliminación de todas las formas de discriminación contra la mujer (CEDAW) es un tratado internacional adoptado en 1979 por la Asamblea General de las Naciones Unidas. "Colección del tratado de las Naciones Unidas" . un.org .

${ }^{5}$ El día 11 de mayo de 2011, el Plenipotenciario de España firmó ad referendum en Estambul el Convenio del Consejo de Europa sobre prevención y lucha contra la violencia contra la mujer y la violencia doméstica, hecho en la
} 
de la protección de las víctimas de violencia de género a los contenidos de las políticas públicas, legislaciones y acciones para prevenir, detectar, proteger y castigar los actos de violencia contra la mujer. Este conjunto de obligaciones prestacionales genera derechos a favor de las víctimas, que a su vez integran el derecho de acceso a la justicia de las mujeres que tienen tal condición.

Es decir, las normas nacionales e internacionales crean los contenidos objetivos y subjetivos del derecho de la mujer a la vida libre de violencia y su consecuente derecho de acceso a la justicia. Entre ellos, el deber de diligencia debida de los Estados, que adopta una doble dimensión de responsabilidad: una dimensión sistémica y una dimensión individual, que a su vez se relaciona con los derechos sociales e individuales, respectivamente. El concepto de "debida diligencia" adquiere una gran importancia en materia de responsabilidad del Estado ${ }^{6}$

Las hijas e hijos de mujeres víctimas de violencia de género sufren una doble victimización, al haber vivido en un ambiente de violencia permanente dirigida en principio hacia sus madres y en el peor de los casos quedar huérfanos por esta lacra social, que puede llegar a ser triple cuando son testigos de este tipo de violencia, siendo uno de los factores de riesgo más importantes relacionados con la seguridad física y emocional de la infancia y adolescencia, pudiendo llegar incluso a causarles la muerte

Estos menores, tras el cese de la convivencia de la pareja no dejan de sufrir puesto que, en la mayoría de los casos, empiezan un régimen de visitas con el padre, situación que los expone, en ocasiones, a posibles nuevos riesgos ${ }^{7}$ en un nuevo tipo de violencia hacia ellos o encaminada hacia la madre a través de ellos ${ }^{8}$, la denominada violencia vicaria ${ }^{9}$.

A pesar de las reformas de $2015^{10}$, en cumplimiento del mandato del artículo 39 de la Constitución Española y de las demandas de cambios sustantivos jurídico-procesales

misma ciudad y fecha. En BOE núm. 137, de 6 de junio de 2014, páginas 42946 a 42976, se publicó el Instrumento de ratificación de dicho convenio, entrando en España en vigor el 1 de agosto de 2014.

${ }^{6}$ MARTÍNEZ GARCÍA, E. "Los deberes del estado en la protección de los derechos de las víctimas de violencia de género y la garantía de acceso a la justicia”, Teoría y derecho: revista de pensamiento jurídico, ISSN 1888-3443, №. 22, (2017), pp. 92-118.

${ }^{7}$ MÚRTULA LAFUENTE, V., El interés superior del menor y las medidas civiles a adoptar en supuestos de violencia de género. Ed. Dykinson, 2016.

${ }^{8}$ PERAL LOPEZ, M.C.: - Madres maltratadas: violencia vicaria sobre hijas e hijos. Universidad de Málaga (UMA), 2018. ISBN 9788417449209. - El fenómeno de la violencia de género a través de las hijas e hijos de madres maltratadas Ed. Diputación Provincial de Jaén ISBN 978-84-09-01570-2, 2018.

${ }^{9}$ RAE (como adjetivo) Vicario: 1. que toma el lugar de otra persona o cosa; sustituto. 2. castigo vicario: sufrido o realizado por una persona en lugar de otra. LILA MURILLO, S. Actitudes y respuestas de la policía ante situaciones de violencia de género en las relaciones de pareja. Instituto de la Mujer, 2009. CASTILLERO MIMENZA, O., “QQué es la violencia vicaria? Un tipo de violencia indirecta que sufren los más desprotegidos: los niños". https://psicologiaymente.net/ forense/violencia-vicaria.

${ }^{10}$ El artículo 39 de la Constitución establece la obligación de los poderes públicos de asegurar la protección social, económica y jurídica de la familia, en especial de los menores de edad, de conformidad con los acuerdos internacionales que velan por sus derechos. En cumplimiento de este mandato, el legislador estatal, en el marco de sus competencias, reguló las instituciones jurídico-públicas y privadas sobre las que se asienta la protección del menor. Ante la demanda de una mejora de sus instrumentos de protección jurídica en aras del cumplimiento efectivo del citado artículo de la Constitución, en 2015 se acometieron importantes modificaciones del sistema de protección a la infancia y a la adolescencia con dos leyes fundamentalmente: la Ley Orgánica 8/2015, de 22 de julio y la Ley 26/2015, de 28 de julio, de modificación del sistema de protección a la infancia y a la adolescencia. Ambas normas desarrollan y refuerzan el derecho del menor a que su interés superior sea prioritario, principio fundamental en esta materia, pero concepto jurídico indeterminado que ha sido objeto, a lo largo de estos años, de diversas interpretaciones. Por ello, para dotar de con- 
en el sistema de protección de menores, se siguen otorgando regímenes de visitas, estancias y comunicaciones a progenitores condenados por malos tratos a la madre. No han aumentado prácticamente las medidas de protección a los menores en estos supuestos en los cuatro años trascurridos desde la entrada en vigor de dichas reformas, probablemente porque la solución no esté en unas reformas, con medidas que facultan y de gran elasticidad y que de poco sirven sin una previa formación especializada real de los operadores jurídicos, que enseñe a detectar los numerosos matices de este tipo de violencia.

En definitiva, se detectan demasiadas cautelas por parte del legislador, que se resiste a la automaticidad en la aplicación de medidas que conlleven supuesto de riesgo o peligro para el o la menor, sin perjuicio de las garantías que se tengan que observar, a la hora de optar por una suspensión de la patria potestad, guarda y custodia o del régimen de visitas en casos de violencia de género ${ }^{11}$. En este sentido, parece ser que el legislador olvida la manipulación e instrumentalización de la que son objeto las y los menores y la victimización a la que quedan expuestas las mujeres que sufren violencia al no poder romper definitivamente todos los vínculos con el agresor y olvida la falta de formación con perspectiva de género ${ }^{12}$ y de sensibilización de dichos operadores jurídicos.

Si bien es cierto que, mientras esa deseada formación deje huella, hay que tomar medidas legales y judiciales, civiles y penales, de protección de los menores que, lejos de la elasticidad de las normas existentes y de la disparidad de las resoluciones judiciales, garanticen la seguridad de los menores que están bajo la patria potestad, la guarda y custodia o el sometimiento a un régimen de visitas, estancias y comunicaciones con un maltratador ${ }^{13}$ y de o ser así el Estado tendrá que asumir su responsabilidad y reparar el daño ${ }^{14}$.

\section{Competencia y responsabilidad del Estado en intervenir con unas políticas reales de prevención y protección adaptadas a la realidad social}

Mientras se ponen en práctica las mejoras pretendidas mediante el Pacto de Violencia de Género, habrá que tomar conciencia del daño que se está cometiendo, asumir la responsabilidad que le corresponde al Estado y articular medidas indemnizatorias al igual que en su día se hizo con las víctimas del terrorismo.

\footnotetext{
tenido al concepto mencionado, se recoge, con el artículo 2, que su interés superior sea una consideración primordial, incorporando tanto la jurisprudencia del Tribunal Supremo de los últimos años y los criterios de la Observación general n. ${ }^{14}$, de 29 de mayo de 2013, del Comité de Naciones Unidas de Derechos del Niño, sobre derechos del niño.

${ }^{11}$ MAGRO SERVET, V., "El régimen de visitas en la violencia de género". Práctica de Tribunales no 100 Sección Práctica Procesal, enero-febrero 2013, La Ley 19268/2012.

${ }^{12}$ TORRES DÍAZ, M.C. "La perspectiva de género como criterio de aplicación jurisprudencial ante la valoración de la intencionalidad del agresor en un contexto patriarcal”. Investigación y Género inseparables en el presente y en el futuro. IV Congreso Universitario Nacional Investigación y Género. Sevilla, 2012.

${ }^{13}$ GUTIÉRREZ ROMERO, F.M., "Incidencias de la violencia de género en el Derecho de Familia: especial tratamiento del régimen de visitas", en Diario La Ley, núm. 7480, año XXXI, La Ley 2010.

${ }^{14}$ PAZ RODRÍGUEZ, J. I., "El llamado Síndrome de Alienación parental. La valoración del daño de las víctimas de la violencia de género". Estudios de Derecho Judicial. Consejo General del Poder Judicial. 2007.
} 
Por un lado, se reconoce como víctimas a madres, hijas e hijos ${ }^{15} \mathrm{y}$, por otro, cada una de estas víctimas, recordando que al ser menores han de tener una especial protección, tendrán que acudir a los Tribunales para que se les reconozca el daño físico y/o moral infringido a estas niñas, niños y adolescentes, a causa del mal funcionamiento de las Administraciones Públicas, vulnerando su derecho fundamental al adecuado desarrollo de su personalidad amparado en el art. 10 de la CE, en el mejor de los casos, y en el peor a su integridad física y a la vida, y al amparo del art 106, es decir, exigir la Responsabilidad Patrimonial de las Administraciones Públicas, regulada en la Ley 39/2015, de 1 de octubre, del Procedimiento Administrativo Común de las Administraciones Públicas ${ }^{16}$ y la Ley 40/2015, de 1 de octubre, del Régimen Jurídico del Sector Público ${ }^{17}$, como una especialidad del procedimiento administrativo común. Por tanto, habrá que evaluar y responder del daño físico y/o moral que se puede infringir a estas niñas, niños y adolescentes a causa de este mal funcionamiento de las Administraciones Públicas, vulnerando su derecho fundamental al adecuado desarrollo de su personalidad amparado en el art. 10 de la CE, y al amparo del art 106 de la Ley 39/2015, de 1 de octubre.

Los casos en que las Administraciones Públicas resultan responsables, de acuerdo con el sistema de Responsabilidad Patrimonial de las Administraciones Públicas están positivados y en los supuestos en que las Administraciones Públicas no resultan responsables les serán de aplicación otros sistemas distintos al indemnizatorio, como el albergado en la Ley 32/1999 de solidaridad con las víctimas del terrorismo ${ }^{18}$ o en el Real Decreto 288/2003, de 7 de marzo, por el que se aprueba el Reglamento de Ayudas y resarcimientos a las víctimas de delitos de terrorismo ${ }^{19}$.

Entre las deficiencias de la ley de violencia de género destaca la regulación de la responsabilidad del Estado y de la administración por victimización secundaria ${ }^{20}$.

Se ha de partir, necesariamente del frontispicio constitucional y, como es sabido, el artículo 106.2 de la CE institucionaliza la Responsabilidad de los poderes públicos como uno más de los requerimientos de todo Estado de Derecho junto con el principio de legalidad, señalando que los particulares, en los términos establecidos en la ley, tendrán derecho a ser indemnizados por toda lesión que sufran en cualquiera de sus bienes y derechos, salvo en los casos de fuerza mayor, siempre que la lesión sea consecuencia del funcionamiento de los servicios públicos. Ahora bien, no es ésta la única referencia constitucional

${ }^{15}$ DEU DEL OLMO, M.I., Hijos e hijas víctimas de violencia de género en la Ciudad de Ceuta. Tesis Doctoral. José Antonio Liébana Checa (dir. tes.), Carmen Villaverde Gutiérrez (dir. tes.), Santiago Real Martínez (dir. tes.) Granada: Universidad de Granada. [http://hdl.handle.net/10481/43005, 2016.

${ }^{16}$ BOE núm. 236, de 02/10/2015.

${ }^{17}$ BOE núm. 236, de 02/10/2015.

${ }^{18}$ BOE núm. 242, de 9 de octubre de 1999.

${ }^{19}$ BOE núm. 65, de 17 de marzo de 2003. Ya en 2015 DAZA reclamaba un tratamiento especial y prioritario para estas víctimas, mediante un paralelismo entre las víctimas de delitos de terrorismo y las víctimas de violencia de género: Vid. DAZA BONACHELA, M. M. "Paralelismos entre terrorismo y violencia machista” Journal of Feminist, Gender and Women Studies 1: 73-83, Enero, 2015.

${ }^{20}$ La victimización secundaria hace referencia a la mala o inadecuada atención que reciben las mujeres víctimas de violencia de género por parte del extenso entramado de instituciones sociales (sistema sanitario, social, policial, judicial, educativo e informativo). RUIZ-RICO RUIZ, Catalina. "Aproximación a los nuevos retos jurídicos de la violencia de género: la responsabilidad pública”. Derecho y Cambio Social ISSN: 2224-4131, 2014. 
que evidencia la importancia que se quiso dar por el constituyente al instituto de la Responsabilidad, sino que ya en el Título Preliminar del citado Texto, concretamente en su artículo 9.3, se garantiza al más alto rango como principio la Responsabilidad de todos los Poderes Públicos, entre los que, señaladamente, se encuentra la Administración.

La responsabilidad de la Administración, como puede constatarse, va a conformarse exclusivamente como objetiva y ello significa que, al igual que en el ámbito del Derecho Privado -en el que encuentra también cabida la responsabilidad sin culpa, por la simple creación de una situación de riesgo-, en el ámbito del Derecho Administrativo la responsabilidad de las Administraciones Públicas también es independiente de cualquier idea de culpa. Incluso la omisión, en la mayoría de los casos, supondrá un funcionamiento anormal según el nivel de diligencia exigible a la Administración ${ }^{21}$.

Pero iría más allá, es necesario ampliar la acción tuitiva asistencial e indemnizatoria de todas las víctimas de violencia de género, bien con carácter directo o subsidiario y añadir la equidad y la solidaridad social como las razones o fundamentos de la respuestas a esta problemática, en la medida en que puede considerarse que las víctimas de violencia de género se encuentran en peor situación que otra clase de grupos que sufren daños.

Resarcir el dolor de las victimas resulta difícil a través de instrumentos jurídicos como la institución de la responsabilidad, la ayuda, la compensación o la pensión. Sólo el fin de la violencia machista acercará los sistemas hacia la inalcanzable reparación integral.

En la Directiva 2012/29/UE por la que se establecen normas mínimas sobre los derechos, el apoyo y la protección de las víctimas de delitos ${ }^{22}$ y por la que se sustituye la Decisión marco 2001/220/JAI del Consejo, se incluye, en el artículo 57, una atención específica a los procesos de victimización secundaria que sufren las víctimas de violencia de género en el ámbito de la justicia. Se exige que los profesionales y las profesionales que hayan de tratar con la víctima antes del proceso penal, durante o después de éste, tengan una formación especializada para facilitar el trato y evitar así situaciones de victimización secundaria ${ }^{23}$.

Por su parte, el Tribunal Europeo de Derechos Humanos en el caso Opuz vs. Turquía ${ }^{24}$, en el que la demandante alegó, en especial, que las autoridades del Estado no la habían protegido a ella ni a su madre de la violencia doméstica, lo que había llevado a la muerte de su madre y a que ella misma fuese maltratada, declaró que "la falla del Estado de proteger a las mujeres contra la violencia doméstica viola el derecho de ellas a igual protección de la ley y esta falla no necesita ser intencional”. La Corte Europea consideró que, aunque la pasividad judicial general y discriminatoria en Turquía no era intencional, el hecho de que afectaba principalmente a las mujeres permitía concluir que la violencia sufrida por las denunciantes podía considerarse violencia basada en género, lo cual es

\footnotetext{
${ }^{21}$ SORO MATEO, B., “Terrorismo y responsabilidad patrimonial de las Administraciones Públicas”, Anales de Derecho. Universidad de Murcia. Número 24. 2006, pp. 251-266.

${ }^{22}$ Diario Oficial de la Unión Europea 14/11/2012. DIRECTIVA 2012/29/UE DEL PARLAMENTO EUROPEO Y DEL CONSEJO de 25 de octubre de 2012 por la que se establecen normas mínimas sobre los derechos, el apoyo y la protección de las víctimas de delitos, y por la que se sustituye la Decisión marco 2001/220/JAI del Consejo.

${ }^{23}$ DOMÍNGUEZ VELA, M., "Violencia de género y victimización secundaria" Revista Digital de Medicina Psicosomática y Psicoterapia. Vol. VI, núm 1, marzo 2016.

${ }^{24}$ Corte Europea de Derechos Humanos, Opuz vs. Turquía, Demanda no 33401/02, Sentencia de 9 de junio de 2009. https://archivos.juridicas.unam.mx/www/bjv/libros/11/5212/18.pdf.
} 
una forma de discriminación en contra de las mujeres. Para llegar a esta conclusión, el Tribunal aplicó el principio según el cual una vez que se demuestra que la aplicación de una regla lleva a un impacto diferenciado entre mujeres y hombres, el Estado debe probar que se debe a factores objetivos no relacionados con la discriminación.

La Corte Europea constató que en el lugar en que vivía la peticionaria se presentaba el número más alto de víctimas de violencia doméstica, que las víctimas eran todas mujeres, que la mayoría de las víctimas eran del mismo origen y, además, que las mujeres víctimas se enfrentaban a problemas cuando denunciaban la violencia, como el hecho que los policías no investigaban los hechos sino que asumían que dicha violencia era un "tema familiar".

Un caso evidente es el asunto González Carreño c. España (Comunicación 47/2012), emitido, el 18 de julio de 2014, por el Comité para la Eliminación de la discriminación contra la mujer, en virtud del Protocolo Facultativo de la Convención sobre la eliminación de todas las formas de discriminación contra la mujer ${ }^{25}$. En este litigio se denuncia, la larga historia de violencias de género vividas por Ángela González Carreño, que concluyen con el terrible asesinato de su hija por parte de su ex pareja y padre de la menor ${ }^{26}$. La resolución recuerda la responsabilidad de los estados y la vinculación entre los estereotipos judiciales y su derecho a un proceso no discriminatorio: "9.7. El comité recuerda que, bajo el artículo 2 (a) de la Convención, los Estados parte tienen la obligación de asegurar por ley u otros medios apropiados la realización práctica del principio de igualdad del hombre y la mujer; y que en virtud de los artículos 2 (f) y 5 (a), los Estados partes tienen la obligación de adoptar medidas (....) Al respecto, el comité destaca que los estereotipos afectan el derecho de la mujer a un proceso judicial imparcial y que la judicatura no debe aplicar estándares inflexibles sobre la base de nociones preconcebidas sobre lo que constituye violencia doméstica." El comité considera que se produce discriminación hacia la demandante, dado que las autoridades del Estado aplicaron nociones estereotipadas que condujeron a no cuestionar el régimen de visitas del padre en un contexto de violencia de género. Caso que finalizó con Sentencia de Tribunal Supremo de 17 de julio de 2018 ${ }^{27}$, Tribunal que reconoció la responsabilidad patrimonial del Estado por daños morales, en base al carácter vinculante del dictamen de CEDAW.

Si bien, por desgracia este no es un caso aislado, causando perplejidad la alegación por Fiscalía de la protección de una mujer asesinada justificándola que 'estaba protegida al vivir con un militar" y de otra mujer asesinada con el arma que fue devuelta por la Administración a un maltratador reincidente. La Audiencia Nacional calificó de "deficiente"

\footnotetext{
${ }^{25}$ http://web.icam.es/bucket/Dict\%C3\%A1men\%20CEDAW\%20\%C3\%81ngela\%20Gonz\%C3\%A1lez\%20Carre\% C3\%B1o.pdf

${ }^{26}$ Mediante sentencia, en 2018, el Tribunal Supremo da eficacia a la decisión del Comité CEDAW sobre un caso de denuncia individual presentado por la Sra. González Carreño contra España. En 1999, cuando su hija Andrea tenía tres años, González Carreño se separó después de que su marido la amenazara con un cuchillo. Durante varios años, la Sra. González Carreño presentó denuncias contra él, con el fin de proteger a su hija y solicitó la suspensión del régimen de visitas. El 24 de abril de 2003, el padre de la menor amenazó a la Sra. González Carreño diciéndole que "le iba a quitar lo que más le importaba", según figura en los documentos del caso examinados por el Comité. Ese mismo día el padre asesinó a la niña de un disparo y posteriormente se suicidó.

${ }^{27}$ STS 17 de julio de 2018, Sala de lo Contencioso, tras desestimar la Audiencia Nacional las pretensiones de la Sra. González Carreño, Roj: STS 2747/2018.
} 
la devolución del arma al agresor por lo que condenó al Estado a pagar 25.000 euros de indemnización a su hija, porque la Administración no comprobó suficientemente los antecedentes del agresor antes de revocar la suspensión de licencia de armas tras dos procesos por violencia de género. En este caso, al valorar la conducta del agresor, únicamente se pidió informe a la fuerza policial donde residía el marido, cuando lo "lógico" hubiera sido solicitarlo en el lugar donde vivía la esposa, pues ya estaban separados, señala la sentencia ${ }^{28}$. El fallo de la Audiencia, que responde a una denuncia de la hija de la víctima, considera que la devolución del arma actuó como "coadyudante de la muerte" de la mujer. La joven, entonces menor de edad, estimaba que la Administración no había tenido en cuenta ningún dato para valorar la peligrosidad de su padre.

Sorprendentemente, en el Estado español, ni Ley Orgánica 1/2004, de 28 de diciembre de Medidas de Protección Integral contra la Violencia de Género ${ }^{29}$, ni las legislaciones autonómica han incluido definiciones de la violencia institucional y, muy escasamente, se hace referencia a los procesos de victimización secundaria, a la obligación de reparación del daño por parte del Estado y a su traducción en indemnizaciones para las víctimas.

Una de las escasas excepciones es la ley catalana, Ley 5/2008, de 24 de abril, del derecho de las mujeres a erradicar la violencia machista, que, aunque rechazó recoger el concepto de violencia institucional, incluye la definición de victimización secundaria (art. $3 \mathrm{~h}$ ) e indica en el artículo $47^{30}$ la necesidad de indemnizar a las mujeres que sufren violencias machistas, reconociendo de esta manera la responsabilidad del Estado.

La retirada de denuncia, el incumplimiento de las órdenes de alejamiento o la renuncia a seguir el procedimiento no puede determinar la conclusión de actuaciones públicas y judiciales sin la evaluación del riesgo de los menores. La protección de los hijos como víctimas de la violencia de género impone deberes a las administraciones implicadas y a los juzgados de violencia de género.

Ahondando en las nefastas consecuencias de la minimización del riesgo en los menores, el estudio realizado por la psicóloga y profesora del área de Psicología Social de la Universidad de Jaén Esther López-Zafra y el psicólogo forense José Carlos Ríos Lechuga en 2017 concluía que la violencia psicológica se hacía crónica, tras la ruptura de la relación de pareja, en el mantenimiento de las relaciones interparentales, en la línea de los hallazgos descritos por Beeble en 2007, que afirmó que un 88\% de los agresores instrumentalizaban a los menores tras la separación ${ }^{31}$. A su vez, en relación al impacto de la exposición a la Violencia de Género en menores en Andalucía, sus resultados fueron concluyentes en cuanto a las secuelas de las y los menores: síntomas depresivos, déficit de autoestima, síntomas relacionados con ansiedad y estrés postraumático, problemas de relación social o

\footnotetext{
${ }^{28}$ RUIZ-RICO RUIZ, C. "Aproximación a los nuevos retos jurídicos de la violencia de género: la responsabilidad pública”. Derecho y Cambio Social ISSN: 2224-4131, 2014. DOMÍNGUEZ VELA, M. "Violencia de género y victimización secundaria" Revista Digital de Medicina Psicosomática y Psicoterapia. Vol. VI, núm 1, marzo 2016.

${ }^{29}$ BOE núm. 313, de 29/12/2004.

${ }^{30}$ El artículo 47 describe las indemnizaciones a las que se obliga el gobierno catalán y que se deben desarrollar reglamentariamente.

${ }^{31}$ LOPEZ-ZAFRA, Esther y RÍOS LECHUGA, José Carlos, “Agresores y relaciones paternofiliales: un riesgo para la infancia". VIII Congreso para el estudio de la Violencia contra las Mujeres. Sevilla 2017.
} 
aislamiento, somatizaciones ${ }^{32}$; y, como patrón de patología externa, presentaban llamadas y búsqueda de atención, agresividad verbal y problemas de conducta.

Consecuencias estas más que suficientes para hacer necesarias la adopción de medidas penales y civiles y no con carácter excepcional como se viene haciendo en la práctica judicial

\section{Protección de las otras víctimas de la violencia de género}

Parece claro que las medidas civiles habrán de adaptarse a las penales vigentes, entre las que se encuentran la suspensión de la patria potestad, guarda y custodia y del régimen de visitas ${ }^{33}$, previstas en los artículos 65 y 66 de la LO 1/2004 de 28 de diciembre, de Medidas de Protección Integral contra la Violencia de Género, reformados por la Ley Orgánica 8/2015, de 22 de julio, de modificación del sistema de protección a la infancia y a la adolescencia. Así, el nuevo artículo 65 establece que "el Juez podrá suspender para el inculpado por violencia de género el ejercicio de la patria potestad, guarda y custodia, acogimiento, tutela, curatela o guarda de hecho, respecto de los menores que dependan de él" y el artículo 66 dispone que "el Juez podrá ordenar la suspensión del régimen de visitas, estancia, relación o comunicación del inculpado por violencia de género respecto de los menores que dependan de él".

A su vez, el artículo 158 del Código Civil, reformado por la Ley 26/2015, de 28 de julio, de modificación del sistema de protección a la infancia y a la adolescencia, añade entre las medidas cautelares a adoptar por el Juez, de oficio o a instancias del propio hijo, de cualquier pariente o del Ministerio Fiscal "dentro de cualquier proceso civil o penal o expediente de jurisdicción voluntaria", las medidas de prohibición de aproximación de los progenitores, tutores, otros parientes o terceras personas al menor, a su domicilio o centro educativo y a otros lugares que frecuente, y de prohibición de comunicación con el menor, impidiendo a los progenitores, tutores, otros parientes o terceras personas establecer contacto escrito, verbal o visual por cualquier medio de comunicación o medio informático o telemático, en ambos casos, con respeto al principio de proporcionalidad (apartados $4{ }^{\circ}$ y $5^{\circ}$ ), y "en general, las demás disposiciones que considere oportunas, a fin de apartar al menor de un peligro o de evitarle perjuicios en su entorno familiar o frente a terceras personas", para lo cual, "se garantizará por el Juez que el menor pueda ser oído en condiciones idóneas para la salvaguarda de sus intereses". Y, por último, "en caso de posible desamparo del menor, el Juzgado comunicará las medidas a la Entidad Pública".

Por tanto, las medidas contempladas en el artículo 158 CC, tienen el carácter de medidas cautelares, se caracterizan por su carácter urgente y necesario y tienen por finalidad

${ }^{32}$ CORSI, J., Maltrato y abuso en el ámbito doméstico. Fundamentos teóricos para el estudio de la violencia en las relaciones familiares. Buenos Aires: Paidós. 2003.

${ }^{33}$ GUTIÉRREZ ROMERO, F.M., "Incidencias de la violencia de género en el Derecho de Familia: especial tratamiento del régimen de visitas”, en Diario La Ley, núm. 7480, año XXXI, La Ley 2010. 
apartar al menor de situaciones puntuales excepcionales de peligro o perjuicio en el entorno familiar o frente a terceros.

A pesar de esta normativa, resultan escasas las medidas civiles de protección dictadas por los Juzgados de Violencia sobre la Mujer, a todas luces, tras los datos publicados por el Consejo General del Poder Judicial a través del Observatorio contra la violencia doméstica y de género.

Desde otra perspectiva, también cabe señalar, la necesidad de coherencia entre los pronunciamientos que pueden efectuarse en el proceso civil y las medidas cautelares adoptadas en el seno del procedimiento penal ${ }^{34}$.

Los asuntos civiles adoptados, en concreto los relativos a la patria potestad, guarda y custodia y régimen de visitas, por los Juzgados de Violencia sobre la Mujer desde el año 2018 hasta 2006, muestran el bajo porcentaje que estas medidas suponen sobre el total de las medidas (civiles y penales) acordadas ${ }^{35}$ :

Mientras que en 2018 y 2017 las Medidas Penales adoptadas eran de un 79,06\% y 80,03\% respectivamente; las civiles 20,94\% y 19,97\%; Suspensión régimen de visitas: 1,05\% y 1,04\%; suspensión de patria potestad: $0,13 \%$ y $0,14 \%$; suspensión de guarda y custodia: 1,74\% y 1,73\%; medidas de protección al menor para evitar peligro o perjuicio (art. 158 Cc): 0,22\% y 0,27\% respectivamente, ya en 2006 las Medidas Penales adoptadas supusieron un 82\%; civiles 18\%; Suspensión régimen de visitas: 1,1\%; suspensión de patria potestad: 0,1\%; suspensión de guarda y custodia: 2\%; medidas de protección al menos para evitar peligro o perjuicio (art. $158 \mathrm{Cc}$ ): $0,1 \%{ }^{36}$

Otro dato a destacar es que, tras las reformas operadas en 2015 en el Código Penal y en la LECrim, sobre todo en materia de medidas de protección a las hijas e hijos de las víctimas de violencia de género, además de la baja proporción de la adopción de estas medidas respecto de las denuncias presentadas, es la disparidad en estas cifras dependiendo del órgano judicial que tenga competencia para resolverlas.

Ya lo ha expuesto el Observatorio contra la violencia doméstica y de género del Consejo General del Poder Judicial que considera preocupantes la constatación de la existencia de una colocación asimétrica ante la ley en la que se situarían algunas interpretaciones existentes respecto de los aspectos que afectan a la seguridad jurídica, ofreciéndose a las víctimas de esta violencia respuestas muy dispares en función de la provincia o la comunidad autónoma en que residen.

\footnotetext{
${ }^{34}$ Entre otros VILLAGRASA ALCAID, C., "Protección en el ámbito civil” Violencia de género: Perspectiva multidiciplinar y Práctica forense. VV.AA. Cizur Menor, Navarra, 2007. MARTÍNEZ GARCÍA, E. “Los procesos por violencia de género: cinco cuestiones procesales y una reflexión" Mujer y Derecho. Jornada por la Igualdad de la Facultad de Derecho. Universitat de Valencia, FABREGAS MONFORT, G. (Coord.) Valencia 2011.

${ }^{35}$ En los datos anuales que publica el CGPJ a través del Observatorio contra la violencia doméstica y de género, se calculan los porcentajes de estas medidas sobre el total de medidas civiles adoptadas, no sobre el total de medidas (civiles y penales). Estadística presentada el 29 de marzo de 2019, relativos al año 2018. Observatorio contra la Violencia Doméstica o de Género. Poder Judicial. http://www.poderjudicial.es/cgpj/es/Temas/Violencia-domestica-y-de-genero/ Actividad-del-Observatorio/Datos-estadisticos/La-violencia-sobre-la-mujer-en-la-estadistica-judicial---Anual-2018.

${ }^{36}$ Vid. Datos calculados sobre el total de medidas adoptadas con los datos anuales que publica el CGPJ a través del Observatorio contra la violencia doméstica y de género. http://www.poderjudicial.es/cgpj/es/Temas/Violenciadomestica-y-de-genero/Actividad-del-Observatorio/Datos-estadisticos/La-violencia-sobre-la-mujer-en-la-estadisticajudicial---Anual-2018.
} 
De los datos que reflejan las medidas civiles acordadas por los Juzgados de los partidos judiciales se desprende que, mientras en unos partidos judiciales se acuerdan un elevado número de medidas civiles en órdenes de protección o como medidas cautelares con respecto a los datos de otros partidos judiciales, en estos otros no se acuerdan prácticamente este tipo de medidas, es más, en algunos partidos judiciales, desde la entrada en vigor de la Ley $1 / 2004$, nunca se ha acordado una medida civil de protección al menor, ni de suspensión de patria potestad, guarda y custodia ni de régimen de visitas, estancias y comunicaciones.

Sirva de ejemplo que, según la estadística anual de 2018 del mencionado Observatorio, del total de las medidas civiles adoptadas, algunos partidos judiciales son los que acordaron el mayor número de ellas, mientras que en otros partidos judiciales, la mayoría, se acordaron una o ninguna en todo el año, a pesar de tener un mayor número de asuntos y dictar, por tanto, mayor número de Órdenes de Protección. Así mientras en partidos judiciales como Alcalá la Real se dictaron 52 suspensiones de regímenes de visitas, 76 en Vinarós, 62 en Barcelona, 25 en Tarragona, 24 en Sevilla, Novelda y en Oviedo, 19 en Jaén, en otros Partidos Judiciales como Alicante con 1 suspensión de régimen de visitas, 1 en Soria, 1 Andújar, 1 Guadalajara, Gerona, Alicante, Elche, Badajoz, Cáceres, Vigo, Getafe, Pamplona, Vitoria, Cádiz o ninguna en Ávila, Salamanca, Albacete, Guadalajara, Toledo, Lleida, Mérida, Teruel, Pamplona, Santa Cruz de Tenerife, León, Bilbao, Segovia, Orense, Zamora, Murcia, Ciudad Real y así hasta 270 partidos judiciales que en todo el año 2018 no acordaron ninguna suspensión del régimen de visitas (en 2017 fueron 272 y en 2016 fueron 238 partidos judiciales los que no acordaron ninguna suspensión de regímenes de visitas estancias y comunicaciones).

En cuanto a la suspensión de la patria potestad, mientras partidos judiciales acuerdan 12 como en Sevilla o 7 en San Boi de Llobregat y en Madrid, o 9 en Tarragona, el resto de partidos judiciales prácticamente no ha acordado ninguna.

Y en los que respecta a la suspensión de guarda y custodia, la mayor parte de los partidos judiciales no acordaron ninguna medida en este sentido, salvo excepciones en partidos judiciales como Arcos de la Frontera 25, Algeciras 20, Granada 25, Santander 24, Orihuela 68, 120 en Barcelona, 28 Vinarós, 27 Novelda, 36 Sueca, 30 Ourense, 70 Zaragoza o 36 en Madrid ${ }^{37}$.

La elasticidad de la pena, que deja a la discrecionalidad del juzgador la imposición de las medidas de protección y/o cautelares, la falta de formación y perspectiva de género hacen que, mientras un juzgador aprecia el riesgo e impone dicha medida otro juzgador opine lo contrario a la hora de actuar o, mejor expresado, deje de actuar.

Algunos colectivos, que incluyen a operadores jurídicos y asociaciones de mujeres, denuncian continuamente falta de formación con perspectiva de género ${ }^{38}$ y sensibilidad

\footnotetext{
${ }^{37}$ Datos de la Estadística presentada el 29 de marzo de 2019, relativos al año 2018. Observatorio contra la Violencia Doméstica o de Género. Poder Judicial. http://www.poderjudicial.es/cgpj/es/Temas/Violencia-domestica-y-de-genero/ Actividad-del-Observatorio/Datos-estadisticos/La-violencia-sobre-la-mujer-en-la-estadistica-judicial---Anual-2018.

${ }^{38}$ MONTALBÁN HUERTAS, I.: - "Perspectiva de género: Criterio de interpretación internacional y constitucional". Madrid: Centro de Documentación Judicial del Consejo General del Poder Judicial. 2004.
} 
del sistema jurídico en los casos de violencia de género. Muchas víctimas dudan y renuncian a denunciar por miedo a perder a sus hijos, pues el arma más poderosa que tiene el maltratador para poder continuar con el maltrato tras el cese de la convivencia son las hijas e hijos y esa arma se la entrega la propia Administración de Justicia.

Desde esta perspectiva, la desigualdad real entre mujeres maltratadas, sus hijas e hijos, dentro de la realidad nacional, presenta una vertiente constitucional que obliga al Estado a asumir una función coordinadora para impedir discriminaciones de las víctimas por razón del territorio. Ya advirtió Amnistía Internacional sobre las posibles desigualdades en la protección de los derechos de las mujeres dependiendo de las diferentes Comunidades Autónomas en las que residan. Así expresaba en su informe: "La desigualdad en la protección por razones geográficas es un aspecto que no ha sido abordado por las autoridades españolas. Las medidas de apoyo integral dirigidas a mujeres presentan diferencias en función de la zona geográfica en que se encuentran, siendo especialmente preocupante lo relativo a la acogida provisional de mujeres maltratadas. El Estado debe asegurar el acceso y la disponibilidad de servicios y recursos de calidad, cuya provisión se corresponda con la obligación de garantizar el ejercicio de derechos".

\section{Conclusiones}

Estos resultados y los demás estudios sobre la materia llevan a concluir que, ¿cómo va a confiar una mujer víctima de violencia de género en las Instituciones si los poderes judiciales descargan en ocasiones la responsabilidad sobre las propias víctimas?

Si bien es cierto que las instituciones, en general, rechazan la violencia de género, en la práctica reconocen que, en frecuentes ocasiones, la falta de coordinación, la escasez de formación específica, la escasez de recursos y ausencia de perspectiva de género hacen que se minimice el riesgo de las víctimas y sus hijas e hijos. Sin embargo algunos de estos motivos tienen fácil remedio y otros son simples escusas, por ejemplo, no se puede alegar la carencia de recursos a la hora de afinar la valoración del riesgo en casos más que evidentes, haciendo caso omiso de los informes de las unidades de valoración forense integral o de servicios sociales, sanitarios o asistenciales ${ }^{39}$.

En nuestro país, la normativa estatal de violencia de género, a diferencia de la Ley 5/2008, de 24 de abril, del derecho de las mujeres a erradicar la violencia machista de Cataluña ${ }^{40}$, no regula un deber de las administraciones de detectar e identificar situaciones de riesgo o existencia de violencia machista.

Sólo desde la perspectiva de los tratados internacionales sobre derechos humanos firmados y ratificados por España, entre los que se destaca Convención para la Eliminación de Todas las Formas de Discriminación contra la Mujer y su Protocolo Facultativo, que obligan al Estado español al cumplimiento de las disposiciones contenidas en ellos al

\footnotetext{
${ }^{39}$ GOMEZ DE TERREROS, I., Los profesionales de la salud ante el maltrato infantil. Ed. Comares. Granada 1997.

${ }^{40}$ BOE núm. 131, de 30 de mayo de 2008.
} 
formar parte del ordenamiento jurídico español y, por tanto, de obligado cumplimiento, está clara esta responsabilidad de las Administraciones competentes. No obstante, habría de plantearse la posible vulneración de los tratados internacionales por nuestras normas de violencia de género, que no reproducen los deberes de los Estados en esta materia.

Si se comprendiera adecuadamente la violencia de género, se entendería que dicha violencia se nutre también de violencias institucionales, de acciones u omisiones realizadas por el Estado y sus autoridades y, ante la imprevisión de responsabilidad estatal por fallos del sistema, se regularía esta materia, no dejando, como en la actualidad, únicamente la facultad para recurrir a la protección internacional derivada de los Tratados ratificados por nuestro país. De modo que en la actualidad la única respuesta posible en estos supuestos consiste en el recurso a instancias internacionales para exigir responsabilidad al Estado por violencia de género, formando parte del grupo de países cuya normativa así lo establece y que tildamos de inferior grado de tutela jurídica en materia de violencia de género y menores.

Mientras se siga pensando por parte de los operadores jurídicos que no hay que suspender los regímenes de visitas y las guardas y custodias a los maltratadores condenados o, de manera preventiva, a los que están siendo investigados por maltrato, el Estado estará asumiendo el riesgo que para las hijas e hijos puede suponer esta convivencia. Habrá que estudiar por qué no se cree a una víctima de violencia de género y dar una solución, pero mientras tanto el Estado tiene que asumir las nefastas consecuencias de la falta de formación específica, tiene que asumir la responsabilidad y reparar ese daño

La realidad es que sigue descendiendo la concesión de medidas de protección y existen muchas diferencias territoriales, hay gran disparidad en las decisiones judiciales.

Hasta el momento no sólo no se hace cargo el Estado, sino que la mujer que protege a sus hijas e hijos tiene que cargar con multas coercitivas, apercibimientos de cambios de custodia y, en el peor de los casos, cambios de custodia y condenas de prisión y multa por delito de desobediencia grave a la autoridad.

La eficacia de las leyes de violencia de género se resiente por la imprevisión de un régimen de sanciones aplicable a las irregularidades, anomalías, errores, negligencias cometidas por la administración y juzgados competentes en esta materia. Paradójicamente, la multiplicidad de medidas garantistas de las mujeres maltratadas por el legislador no se ha implementado con la incorporación de mecanismos jurídicos y acciones específicas para la exigencia de responsabilidades administrativas y judiciales.

La irresponsabilidad del Estado y de las Administraciones Públicas en la protección de las víctimas de violencia de género, mujeres maltratadas y sus hijas e hijos, afecta al derecho a la tutela judicial efectiva.

\section{Referencias bibliográficas}

ACALE SÁNCHEZ, M.: - "El niño como víctima de los malos tratos en el ámbito familiar" Cursos de derechos humanos de Donostia-San Sebastián, Vol. 4, 2003, ISBN 84-8373558-X, pp. 11-38. 
- "Aspectos penales del pacto de estado español contra la violencia de género de 2017". Diritto Penale Comtemporaneo. https://www.penalecontemporaneo.it/upload/7538acalesanchez118.pdf.

AGUILAR REDORTA, D.: - VV.AA., Aclaraciones sobre el "síndrome de alienación parental". AGUILAR REDORTA, D. (2007). American Juornal of Forensic Psychology, Volume 19, (2001/31).

- "La infancia víctima de violencia de género", III Congreso del Observatorio contra la violencia doméstica y de género, 2009.

CASTILLEJO MANZANARES, R., "El estatuto de la víctima y las víctimas de violencia de género". Diario La Ley no 8884, 2016

CASTILLERO MIMENZA, O., “QQué es la violencia vicaria? Un tipo de violencia indirecta que sufren los más desprotegidos: los niños". https://psicologiaymente.net/forense/ violencia-vicaria.

CORSI, J., Maltrato y abuso en el ámbito doméstico. Fundamentos teóricos para el estudio de la violencia en las relaciones familiares. Buenos Aires: Paidós. 2003

CUADRADO RUIZ, M.A., "Violence against women. Forced marriages" en VII IFCCLGE, Paper Collection, Beijing, 2015.

DAZA BONACHELA, M. M. "Paralelismos entre terrorismo y violencia machista" Journal of Feminist, Gender and Women Studies 1: 73-83, Enero/January 2015.

DEU DEL OLMO, M.I., Hijos e hijas víctimas de violencia de género en la Ciudad de Ceuta. Tesis Doctoral. José Antonio Liébana Checa (dir. tes.), Carmen Villaverde Gutiérrez (dir. tes.), Santiago Real Martínez (dir. tes.) Granada: Universidad de Granada. http://hdl. handle.net/10481/43005, 2016.

DIEZ GARCÍA, H., "Comentario al art. 158 del Código Civil ". Comentarios al Código Civil Tomo II (arts. 152 a 360). BERCOVITZ RODRÍGUEZ-CANO, Rodrigo (dir.) Tirant lo Blanch. Valencia 2013.

DOMÍNGUEZ VELA, M., "Violencia de género y victimización secundaria” Revista Digital de Medicina Psicosomática y Psicoterapia. Vol. VI, núm 1, marzo 2016.

FERNÁNDEZ RODRÍGUEZ LIÉVANA, G. Los estereotipos de género en los procedimientos judiciales por violencia de género: el papel del Comité CEDAW en la eliminación de la Discriminación y de la Estereotipación. Oñati Socio legal Series, vol 5, no 2, 2015.

GIL RUIZ, J.M., "Derechos Humanos, violencia de género y maltrato jurídico. Bases para entender el tratamiento integral de la violencia de género". https://dialnet.unirioja.es/ descarga/articulo/2220951.pdf

GOMEZ DE TERREROS, I., Los profesionales de la salud ante el maltrato infantil. Ed. Comares. Granada 1997.

GRANADOS PÉREZ, C., Acuerdos del Pleno de la Sala Penal del Tribunal Supremo para unificación de la Jurisprudencia. Años 1991-2016. Actualizados hasta julio de 2016. 2 a ed. Tirant lo Blanch. 2017.

GUTIÉRREZ ROMERO, F.M., "Incidencias de la violencia de género en el Derecho de Familia: especial tratamiento del régimen de visitas", en Diario La Ley, núm. 7480, año XXXI, La Ley 2010. 
HIRIGOYEN, M-F.: El maltrato en la vida cotidiana. Buenos Aires, Editorial Paidós, 2003. - Mujeres maltratadas. Paidós, Barcelona, 2003.

LILA MURILLO, S. Actitudes y respuestas de la policía ante situaciones de violencia de género en las relaciones de pareja. Instituto de la Mujer, 2009.

LORENTE ACOSTA, M.: - "Síndrome de agresión a la mujer. Síndrome de maltrato a la mujer". Revista de Ciencia Penal y Criminología RECPC 02-07. 2000.

- Mi marido me pega lo normal. Barcelona: Planeta. 2003.

- El Rompecabezas. Anatomía del maltratador. Barcelona: Editorial Crítica, 2004.

MAGRO SERVET, V.: - "La valoración de la declaración de la víctima en el proceso penal". Diario La Ley no 7012-7013, 2008

- "El régimen de visitas en la violencia de género". Práctica de Tribunales no 100 Sección Práctica Procesal, enero-febrero 2013, La Ley 19268/2012.

- "Medidas incluidas en la Ley Orgánica 8/2015, de 22 de julio y Ley 26/2015, de 28 de julio, de modificación del sistema de protección a la infancia y a la adolescencia, afectantes a la violencia de género". La Ley Derecho de Familia, 13 de octubre de 2015, La ley 6045/2015.

MAQUEDA ABREU, M. L.: - "La violencia habitual en el ámbito familiar: razones de una reforma", en: VV.AA., El nuevo derecho penal español. Estudios penales en memoria del profesor José Manuel Valle Muñiz. Pamplona: Aranzadi, 2001, p. 1525.

- “Es la estrategia penal una solución a las violencias contra las mujeres? Algunas respuestas desde un discurso feminista crítico", Revista para el análisis del Derecho, núm. 4, 2007.

MARÍN DE ESPINOSA CEBALLOS, E. B., "La intervención del derecho penal en los castigos a los hijos: Un análisis comparado" Revista Electrónica de Ciencia Penal y Criminología. RECPC 01-07 (1999).

MARTÍNEZ GARCÍA, E.: - "Los procesos por violencia de género: cinco cuestiones procesales y una reflexión" Mujer y Derecho. Jornada por la Igualdad de la Facultad de Derecho. Universitat de Valencia, FABREGAS MONFORT, Gemma. (Coord.) Valencia 2011. - "Los deberes del estado en la protección de los derechos de las víctimas de violencia de género y la garantía de acceso a la justicia", Teoría y derecho: revista de pensamiento jurídico, ISSN 1888-3443, №. 22, 2017, pp. 92-118.

MONTALBÁN HUERTAS, I.: - "Perspectiva de género: Criterio de interpretación internacional y constitucional". Madrid: Centro de Documentación Judicial del Consejo General del Poder Judicial. 2004.

- "Malos tratos, violencia doméstica y violencia de género desde el punto de vista jurídico". Revista de Ciencias Sociales del Instituto Universitario de Investigación, nº 12. 2007.

MORILLAS CUEVA, L., "Violencia de género versus violencia doméstica. Una reflexión a propósito de la Ley Integral", en VV.AA. La ley integral. Un estudio multidisciplinar. Madrid: Dykinson. 2009. pp. 20 y ss.

MUÑOZ CONDE, F., "Violencia familiar y de género en la Ley Orgánica 1/2004". En Estudios sobre la tutela penal en violencia de género, coord., por Núñez Castro, E. Editorial Tirant, 2010, pp. 30 y 31. 
MÚRTULA LAFUENTE, V., El interés superior del menor y las medidas civiles a adoptar en supuestos de violencia de género. Ed. Dykinson, 2016.

PAZ RODRÍGUEZ, J. I., "El llamado Síndrome de Alienación parental. La valoración del daño de las víctimas de la violencia de género". Estudios de Derecho Judicial. Consejo General del Poder Judicial. 2007.

PERAL LÓPEZ, M. C.: - "El supremo interés del menor. Víctimas de la violencia de género" en CUADRADO RUIZ, M Ángeles, Cuestiones penales. A propósito de la Reforma penal de 2015, Madrid 2016, pp. 55 y ss.

- "Efectos de la privación de la Patria Potestad. Referencia al régimen de visitas". Actualidad Civil. Wolters Kluwer 2017, pp. 16-30.

- "Efectos de la privación de la patria potestad. Referencia al régimen de visitas, comunicaciones y estancias”. Revista Digital Familia y Sucesiones, núm. 19, julio 2017. Editorial jurídica Sepin.

- La práctica judicial en los delitos de malos tratos: Patria potestad, guarda y custodia y régimen de visitas. Granada: [http://hdl.handle.net/10481/47880]. Universidad de Granada, 2017.

- Madres maltratadas: violencia vicaria sobre hijas e hijos. Universidad de Málaga (UMA), 2018. ISBN 9788417449209.

- El fenómeno de la violencia de género a través de las hijas e hijos de madres maltratadas Ed. Diputación Provincial de Jaén ISBN 978-84-09-01570-2, 2018.

PEREZ DEL CAMPO, A. M. “Los hijos como instrumento de la venganza del agresor”. 2012 Público.

REYES CANO, P.: - "Menores y violencia de género: de invisibles a visibles". Revista de la Cátedra Francisco Suárez, 49, 2015 pp. 181-201.

- "La patria potestad a examen ante la violencia de género". Anales de la Cátedra Francisco Suarez. Vol. 51, 2017, pp. 335-356.

RODA Y RODA, D. El interés del menor en el ejercicio de la patria potestad Ed. Aranzadi 2014.

RUIZ-RICO RUIZ, C. “Aproximación a los nuevos retos jurídicos de la violencia de género: la responsabilidad pública". Derecho y Cambio Social ISSN: 2224-4131, 2014.

SEPÚLVEDA GARCÍA DE LA TORRE, Á. "La violencia de género como causa de maltrato infantil". Publicado en Cuad. Med. Forense, 12, pp. 43-44, Enero-Abril 2006.

SORO MATEO, B., "Terrorismo y responsabilidad patrimonial de las Administraciones Públicas", Anales de Derecho. Universidad de Murcia. Número 24, 2006, pp. 251-266.

TORRES DÍAZ, M.C. “La perspectiva de género como criterio de aplicación jurisprudencial ante la valoración de la intencionalidad del agresor en un contexto patriarcal". Investigación y Género inseparables en el presente y en el futuro. IV Congreso Universitario Nacional Investigación y Género. Sevilla, 2012.

VACCARO, S. "Violencia Vicaria: Las hijas y los hijos víctimas de la Violencia contra sus madres." http://www.tribunafeminista.org/2016/03/violencia-vicaria-las-hijas-ylos-hijos-victimas-de-la-violencia-contra-sus-madres.

VILLAGRASA ALCAID, C., "Protección en el ámbito civil" Violencia de género: Perspectiva multidiciplinar y Práctica forense. Cizur Menor, Navarra, 2007. 
VV.AA., "La violencia de género y la violencia doméstica en el contexto legislativo español: de la aprobación de la ley orgánica de medidas de protección integral contra la violencia de género a la reforma del Código Penal de 2015” ALASTUEY DOBÓN, MC. Revista de Derecho Penal no 23, 2015 pp. 27-78.

VV.AA., Violencia doméstica, divorcio y adaptación psicológica. De la disarmonía familiar al desarrollo de los hijos. CANTÓN DUARTE, J. Madrid, Pirámide. 2013.

VV.AA., "La violación como episodio concreto del maltrato doméstico a la luz de la jurisprudencia más reciente”. En Estudios penales sobre violencia doméstica.; CARMONA SALGADO, C. Editoriales de Derechos Reunidos EDERSA, 2002, pp. 509-528.

VV.AA., "Víctimas de Violencia Familiar: Consecuencias psicológicas en hijos de mujeres Maltratadas". Anales de Psicología, Junio, año 2005/Vol.21. № 001. CORBALÁN, F. J. Y PATRÓ, R. Universidad Murcia. España. pp.11-17.

VV.AA., "El delito de malos tratos en el ámbito familiar: artículo 153 del Código Penal". CUADRADO RUIZ, M.A. La Ley: Revista jurídica española de doctrina, jurisprudencia y bibliografía, $N^{\circ}$ 4, 2000, pp. 1560-1566.

VV.AA., VIII Congreso para el estudio de la Violencia contra las Mujeres. "Agresores y relaciones paternofiliales: un riesgo para la infancia”. LOPEZ-ZAFRA, E. y RÍOS LECHUGA, J.C. Sevilla 2017.

VV.AA, Agresión a la mujer: Maltrato, violación y acoso. LORENTE ACOSTA, M., Comares 1999. VV.AA. La protección de la víctima de violencia de género. Un estudio multidisciplinar tras diez años de aprobación de la Ley Orgánica 1/2004. ROMERO BURILLO, A.M. Aranzadi Cizur Menor Navarra, 2016.

ROSSER LIMIÑANA, A.M. Menores expuestos a violencia de género. Cambios legislativos, investigación y buenas prácticas en España. Papeles del Psicólogo / Psychologist Papers, 2017. Vol. 38(2), pp. 116-124.

VV.AA. Estudios número 18 "Análisis jurídico de la violencia contra las mujeres. Guía de argumentación para operadores jurídicos". RUBIO CASTRO, A.M., Instituto Andaluz de la Mujer. Sevilla 2004. 